\title{
Methodologies for Large-Size Pouch Lithium-Ion Batteries End-of-Life Gateway Detection in the Second-Life Application
}

To cite this article before publication: Pierrot S. Attidekou et al $2020 \mathrm{~J}$. Electrochem. Soc. in press https://doi.org/10.1149/1945-7111/abd1f1

\section{Manuscript version: Accepted Manuscript}

Accepted Manuscript is "the version of the article accepted for publication including all changes made as a result of the peer review process, and which may also include the addition to the article by IOP Publishing of a header, an article ID, a cover sheet and/or an 'Accepted

Manuscript' watermark, but excluding any other editing, typesetting or other changes made by IOP Publishing and/or its licensors"

This Accepted Manuscript is $\odot 2020$ The Author(s). Published by IOP Publishing Ltd..

This article can be copied and redistributed on non commercial subject and institutional repositories.

Although reasonable endeavours have been taken to obtain all necessary permissions from third parties to include their copyrighted content within this article, their full citation and copyright line may not be present in this Accepted Manuscript version. Before using any content from this article, please refer to the Version of Record on IOPscience once published for full citation and copyright details, as permissions will likely be required. All third party content is fully copyright protected, unless specifically stated otherwise in the figure caption in the Version of Record.

View the article online for updates and enhancements. 


\section{Methodologies for Large-Size Pouch Lithium-Ion Batteries End-of-Life Gateway Detection in the Second-Life Application}

\begin{tabular}{|r|l|}
\hline Journal: & Journal of The Electrochemical Society \\
\hline Manuscript ID & JES-102165.R2 \\
\hline Manuscript Type: & Research Paper \\
\hline Dathor: & 20-Nov-2020 \\
\hline Complete List of Authors: & $\begin{array}{l}\text { Attidekou, Pierrot; Newcastle University } \\
\text { Milojevic, Zoran; Newcastle University, } \\
\text { Muhammad, Musbahu; Teesside University, School of Computing } \\
\text { Engineering and Digital Science } \\
\text { Ahmeid, Mohamed; Newcastle University, School of Engineering } \\
\text { Lambert, Simon; Newcastle University } \\
\text { Das, Prodip; Newcastle University, School of Engineering }\end{array}$ \\
\hline Keywords: & $\begin{array}{l}\text { Batteries - Li-ion, Energy Storage, Gateway detection, Thermal imaging, } \\
\text { Reuse and re-purposing }\end{array}$ \\
\hline & \\
\hline
\end{tabular}




\title{
Methodologies for Large-Size Pouch Lithium-Ion Batteries End-of-Life Gateway Detection in the Second-Life Application
}

\author{
Pierrot S. Attidekou, ${ }^{1}$ Zoran Milojevic, ${ }^{1}$ Musbahu Muhammad, ${ }^{2}$ Mohamed Ahmeid, ${ }^{1}$ Simon \\ Lambert, ${ }^{1}$ and Prodip K. Das ${ }^{1, z}$ \\ ${ }^{1}$ School of Engineering, Newcastle University, Newcastle upon Tyne, NE1 7RU, United Kingdom \\ ${ }^{2}$ School of Computing, Engineering \& Digital Technologies, Teesside University, Middlesbrough, \\ TS1 3BX, United Kingdom
}

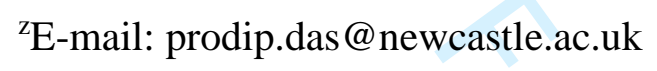

\section{ABSTRACT}

In electric vehicles, the battery pack is deemed to reach the end-of-life (EoL) when the capacity of the lithium-ion batteries (LiBs) drops below $80 \%$ of their nominal capacity. This leads to an emerging market of reuse and repurposing of retired LiBs in less power demanding applications. However, longevity, safety, higher performance and system warranty are the requirements of such a novel market and detecting batteries degradation level and their "real" EoL in the second-life applications before recycling is paramount. Here, we present a combination of diagnosis methodologies applied on large-size pouch LiBs from a dismantled first-generation/Nissan Leaf retired battery pack, cycled with different accelerated ageing cycling procedures. While the capacity-based state of health is limited, the degradation modes and the "real" EoL were successfully detected by the incremental capacity analysis (ICA) and infrared (IR) thermal techniques. The ICA and IR measurements can be utilised to detect quantitative changes or different qualitative spacious non-uniform ageing changes over the large-size LiB's surface. Moreover, these methodologies represent an important first step for "real" EoL prediction a hundred cycles earlier and can be applied on large-size pouch cells with different chemistries in second-life applications. 


\section{Introduction}

Lithium-ion batteries ( $\mathrm{LiBs}$ ) are ubiquitous in our daily life, from electronic devices to electric vehicles (EVs). In recent years, the EV and hybrid electric vehicle (HEV) market has grown several folds to decarbonisation. Besides, the battery's second-life market is emerging from the retired $\mathrm{EV}$ which represents the first step before the ultimate recycling and materials recovery. In vehicular application, when the end-of-life $(\mathrm{EoL})$ is reached, around $80 \%$ of the batteries capacity remained and can be reused in less power demanding applications such as energy storage system (BESS) for domestic or industrial applications. ${ }^{1}$ To enable this market for second use batteries, ${ }^{2}$ it is necessary to demonstrate the capability of such batteries in realworld scenarios, validating their longevity in these applications is critical. The potential of second-life batteries lies in their state-of-health $(\mathrm{SoH})$ or remaining useful life. ${ }^{3}$ A work has already been reported on the characterisation of the vehicular life up to the EoL. ${ }^{4}$ It is essential to conduct several studies to ascertain the viability of this market in all aspects. More importantly, the degradation beyond EoL should be monitored to establish a safety threshold for risk mitigation before recycling.

The health of a battery deteriorates over time due to both cycling (application-based), calendar aging, intrinsic and extrinsic parameters, such as the temperature. To trace these parameters, many sensor technologies have been developed. The electrochemical impedance spectroscopy (EIS) is used to monitor the intrinsic resistance growth that strongly depends on the state-of-charge (SoC) and temperature. ${ }^{5}$ This enables the development of an equivalent circuit model (ECM) for the assessment of the battery Ohmic resistance, the charge transfer resistance, the diffusion and the electrode degradation. Different ECMs have been proposed in the literature, including the adatom model and the single-particle model. ${ }^{6,7}$ Generally, the SoH of a battery is mainly based on capacity tracking. ${ }^{8}$ Whilst capacity-based $\mathrm{SoH}$ methods yield approximately accurate results, the measurements are time-consuming as the process requires the battery to be fully cycled, using the constant current and constant voltage methods.

The incremental capacity analysis (ICA) and differential voltage analysis (DVA) are nondestructive techniques (NDT) that give more reliable and effective information on degradation at electrode levels capable of identifying battery ageing mechanisms with a high degree of fidelity. ${ }^{9-11}$ The underlying degradation mechanisms of LiB include loss of active material (LAM), loss of lithium inventory (LLI), accelerated growth of surface electrolyte interphase (SEI), alteration of the surface areas of the electrodes especially on the anode, 
volume expansion of the active material of the electrode, structural modifications of the cathode material, manganese dissolution and lithium plating. ${ }^{12-14}$

Infrared (IR) thermography could be a useful NDT for temperature field measurements over the battery surface. ${ }^{15-19}$ For LiBs, IR thermography was mostly used to validate calculated temperature over the LiBs surface obtained using electrochemical-thermal or electro-thermal coupled models with experimental measurements on the pristine LiBs. ${ }^{20-23}$ During the cycling of large-size LiBs, there could be variations of voltage, transverse current density and local SoC over LiB's surface even for a brand-new battery. ${ }^{24,} 25$ These variations together with battery dimensions, operating temperature and C-rate lead to the non-uniform local heat generation rates, non-uniform temperature distribution and in-plane temperature gradients for large-size pouch batteries which increase with battery ageing, especially in the second-life applications. This will lead to battery ageing non-uniformities and increased local resistance over the battery surface as well as localised hot-spots and severe temperature gradients. ${ }^{26,27}$

Up to date, the literature on LiBs for second-life applications is sparse and the investigation should be conducted step by step. ${ }^{28}$ It is therefore strongly recommended to establish baseline studies of the SoH that should not as usual merely address the capacity and the resistance but a number of the safety aspects including the thermal aspects etc. In both EV and post EV lives, different aging mechanism modes will lead to the ultimate failure of the battery. These failure modes include resistance increase, SEI layers thickness increase, manganese dissolution at the cathode, lithium plating, etc. These degradation signatures are capable of causing non-uniform current distribution that can be associated with different heat generation over the battery surface. The detection of these thermal variations can be strictly correlated with the aforementioned failure modes. In this work, we have presented and compared different methodologies (capacity-based SoH, ICA, and IR thermography) with the potential of identifying "real" EoL in large-size pouch LiBs in second-life applications a hundred cycles earlier.

\section{Experimental}

In this study, two disassemble batteries from the first generation Nissan Leaf module (lithium manganese oxide (LMO) with lithium nickel oxide (LNO) cathode and graphite anode) were employed to assess their longevity in second-life applications. The module contains four batteries and the batteries tested were positioned in the middle of the module. The batteries were characterised (capacity, ICA, and thermal imaging) after disassembly and each one is 
subjected to a different accelerated ageing procedure. The specifications of both batteries are displayed in Table 1.

Table 1. Specification of the batteries cycled with different cycling procedures

\begin{tabular}{|c|c|c|c|c|c|c|c|}
\hline & $\mathbf{Q}_{\text {nom }} / \mathbf{A h}$ & $\mathbf{V}_{\text {nom }} / \mathbf{V}$ & $\begin{array}{c}\text { Energy } \\
\text { density }_{\text {nom }} / \text { whkg }^{-1}\end{array}$ & $Q_{N=0} / A h$ & $\mathrm{SoH}_{\mathrm{N}=0}$ & $\begin{array}{l}\text { Dimensions } \\
\mathrm{L} \times \mathrm{W} \times \mathrm{T} / \mathrm{mm}\end{array}$ & Weight/g \\
\hline$\overline{\mathrm{CP1}}$ & 325 & 375 & 157 & & $85.8 \%$ & & \\
\hline CP2 & 32.5 & & 157 & 27.7 & $85.2 \%$ & & \\
\hline
\end{tabular}

\section{Cycling Procedures}

The first cycling procedure (CP1) consists of charging with a constant current (CC) of 55A slightly above the threshold of $4.2 \mathrm{~V}$ to $4.4 \mathrm{~V}$, upon reaching $4.4 \mathrm{~V}$ it is not allowed to enter into the constant voltage $(\mathrm{CV})$ phase but rather relaxed for 2 hours. To complete the cycle, the battery is then discharged to $3.6 \mathrm{~V}$ followed by a CV phase of 30 minutes and 1-hour relaxation.

In the second cycling procedure (CP2), the battery is charged to $4.4 \mathrm{~V}$ with a $\mathrm{CC}$ of $55 \mathrm{~A}$ and then held at a $\mathrm{CV}$ of $4.4 \mathrm{~V}$ until the current drops to less than $\mathrm{C} / 20$ (i.e. $\mathrm{I}<\mathrm{C} / 20$ ). The battery is then allowed to rest for 2 hours followed by a CC-CV discharge to $4.2 \mathrm{~V}$ and another rest for 2 hours. Finally, the battery is further discharged to $3.6 \mathrm{~V}$ based on $\mathrm{CC}-\mathrm{CV}$ and rests for 2 hours before the subsequent cycle ensue. This is done to identify the key stress-induced degradation process that occurs when batteries are operated under conditions of cycling rate that are outside the nominal operating regimes. Both experimental procedures $(\mathrm{CP} 1$ and $\mathrm{CP} 2)$ were conducted in an environmental simulation chamber (Binder $\mathrm{GmbH})$ at $25^{\circ} \mathrm{C}$.

It is worth noting that $\mathrm{CP} 1$ can be considered as a mild overcharge regime where according to our hypothesis, SEI growth will lead to local resistance increase, cathode delithiation and eventually lithium plating should be expected. Conversely, CP2 can be considered as severe degradation related to overcharging, including SEI and hence resistance growth, electrolyte decomposition can be expected in addition to lithium plating and manganese dissolution that should be responsible for a collapse of the cathode material crystal structure. ${ }^{29-32}$

\section{Reference Performance Test (RPT)}

After every 50 cycles, basic RPT (capacity and thermal imaging) was performed which comprises capacity and thermal imaging. For the capacity check, the battery is cycled using 
CC-CV (using $50 \mathrm{~A}$ ) and the capacity is measured. For thermal imaging, the battery temperature is measured by the thermal camera (FLIR A655 sc) within the environmental chamber during the discharge cycle. The battery surface was painted by Tetanal Camera Varnish Spray/Black paint, with a measured emissivity value of 0.96 to eliminate reflection. A customised battery holder made from POM-C acetal solid plastic material and aluminium plates is used to keep the battery stable during imaging and facilitate connection with the tabs.

\section{Results and Discussion}

\section{State of health}

Figure 1 depicts the voltage versus capacity obtained upon discharge under the RPT for two cycling procedures and the state of health $(\mathrm{SoH})$ for both batteries. As observed, both capacity and voltage decrease with the cycling numbers and the rate of changes in capacity and voltage can be associated with the difference in cycling protocols.
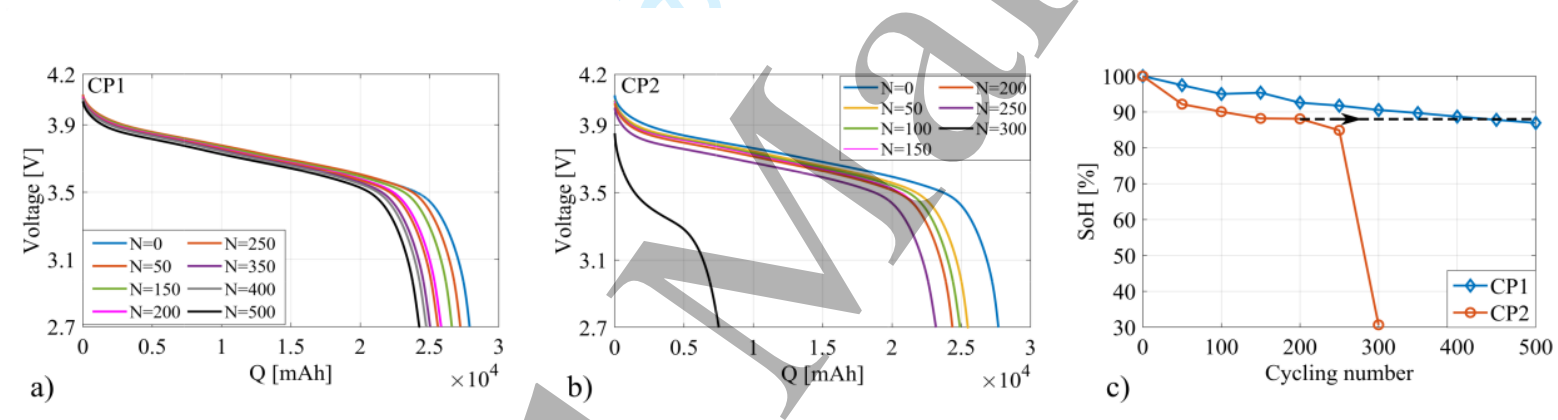

Figure 1. Discharge profiles under thermal image investigation: (a) voltage versus capacity at constant current using the first cycling procedure (CP1), (b) voltage versus capacity at constant current using the second cycling procedure (CP2) and (c) capacity-based SoH for both batteries.

For SoH (Figure 1c), after 500 cycles, $87.12 \%$ of capacity is remaining in the battery cycled with CP1 compared to that of $\mathrm{CP} 2$ that has reached its knee at 250 cycles, with only $~ 30 \%$ capacity left after 300 cycles. It should be noted almost the same $\mathrm{SoH}$ at 200 and 450 cycles for $\mathrm{CP} 2$ and $\mathrm{CP} 1$, respectively. Here the $\mathrm{SoH}$ is the ratio in percentage between the capacity at any time during aging to the capacity at the beginning of the second life.

\section{Incremental capacity analysis}

The incremental capacity analysis (ICA) is a useful technique that transforms the voltage plateau into visible $\pm \mathrm{dQ} / \mathrm{dV}$ peaks/valleys. Like potentiostatic related curve, where each peak/valley provides information upon intercalation mechanisms that describe biphasic regions, associated with phase transition during charge/discharge processes. The position of 
peaks/valleys is a distinctive signature of electrode materials. Usually, this technique is performed at a low C-rate. When performed at a higher C-rate up to $4 \mathrm{C}$ as $\mathrm{in}^{33,34}$, the resolution can be improved by filtering to obtain reasonably correct and acceptable ICA peaks/valleys position.

The change in capacity upon aging can be strongly related to the change in the loading ratio (LR) and offset (OFS). The LR is the capacity ratio between the negative electrode (NE) and the positive electrode (PE) and its variation during aging is responsible for severe deterioration processes. The degradation caused by the variation of LR during aging can be associated with the loss of active material (LAM) during lithiation LAM $_{\mathrm{LiPE}}$ and LAM $_{\mathrm{LiNE}}$ of the positive and negative electrode respectively. Conversely during de-lithiation to LAM $\mathrm{dePE}_{\mathrm{d}}$ and $\mathrm{LAM}_{\mathrm{deNE}}$ for the positive and negative electrode respectively. Alternatively, the OFS is the shift between PE and NE created during the formation of the irreversible protective SEI layer that clearly describes the lithium loss inventory (LLI) involved in the aging mechanisms. ${ }^{35-40}$

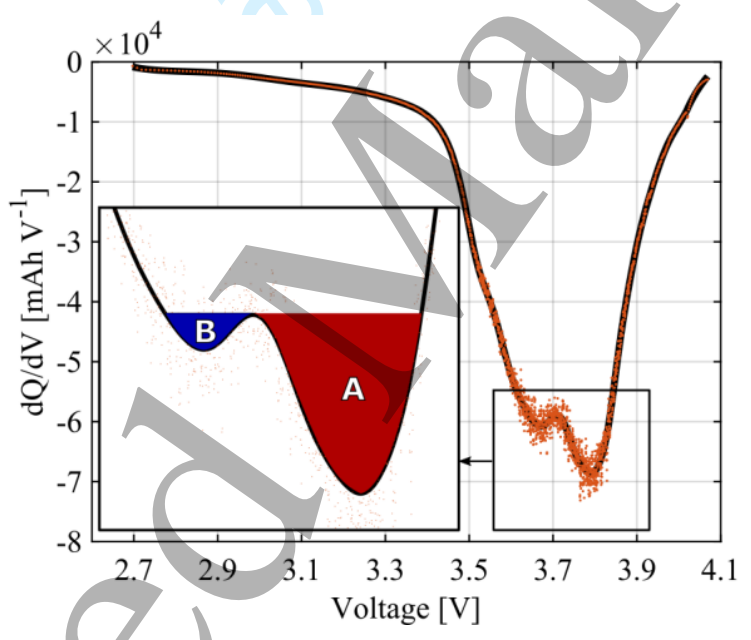

Figure 2. Typical incremental capacity analysis as processed with noise, the insert depicts the area at $3.8 \mathrm{~V}$ and $3.65 \mathrm{~V}$.

Figure 2 represents a typical incremental capacity curve for both filtered (solid line) and nonfiltered (dots) with two distinctive 'valleys' around $3.8 \mathrm{~V}$ and $3.65 \mathrm{~V}$, which areas are marked $\mathrm{A}$ and $\mathrm{B}$, respectively. Here a Savitsky-Golay filtering technique was used for filtering purposes ${ }^{41}$ Figures 3 and 4 show the evolution of valleys (A and B) upon ageing for CP1 and $\mathrm{CP} 2$ cases, respectively. The height of the ICA valley around $3.8 \mathrm{~V}$ is greater than that of $3.65 \mathrm{~V}$ at zero cycle for $\mathrm{CP} 1$ and then gradually decreasing during ageing, while that of the valley at $3.65 \mathrm{~V}$ is increasing. In addition, the valley at $3.8 \mathrm{~V}$ shifts toward higher voltage 
with aging up to 350 cycles and later shifts back toward lower voltage between 350 to 500 cycles. No obvious shift is observed for the valley at $3.65 \mathrm{~V}$.

For CP2 (Figure. 4), the evolution of the height of the ICA valley around $3.8 \mathrm{~V}$ is monotonously greater than that at $3.65 \mathrm{~V}$ between 0 to 150 cycles with no apparent shift. However, the valley shifts slightly toward lower voltage up to 200 cycles before shifting back to the initial position at the end of 250 cycles. These valleys (Figure. 4) have disappeared completely on reaching 300 cycles and a new valley has appeared around $3.35 \mathrm{~V}$. This indicates both the loss of active material and the lithium loss inventory involved in the aging at 300 cycles. $^{3}$
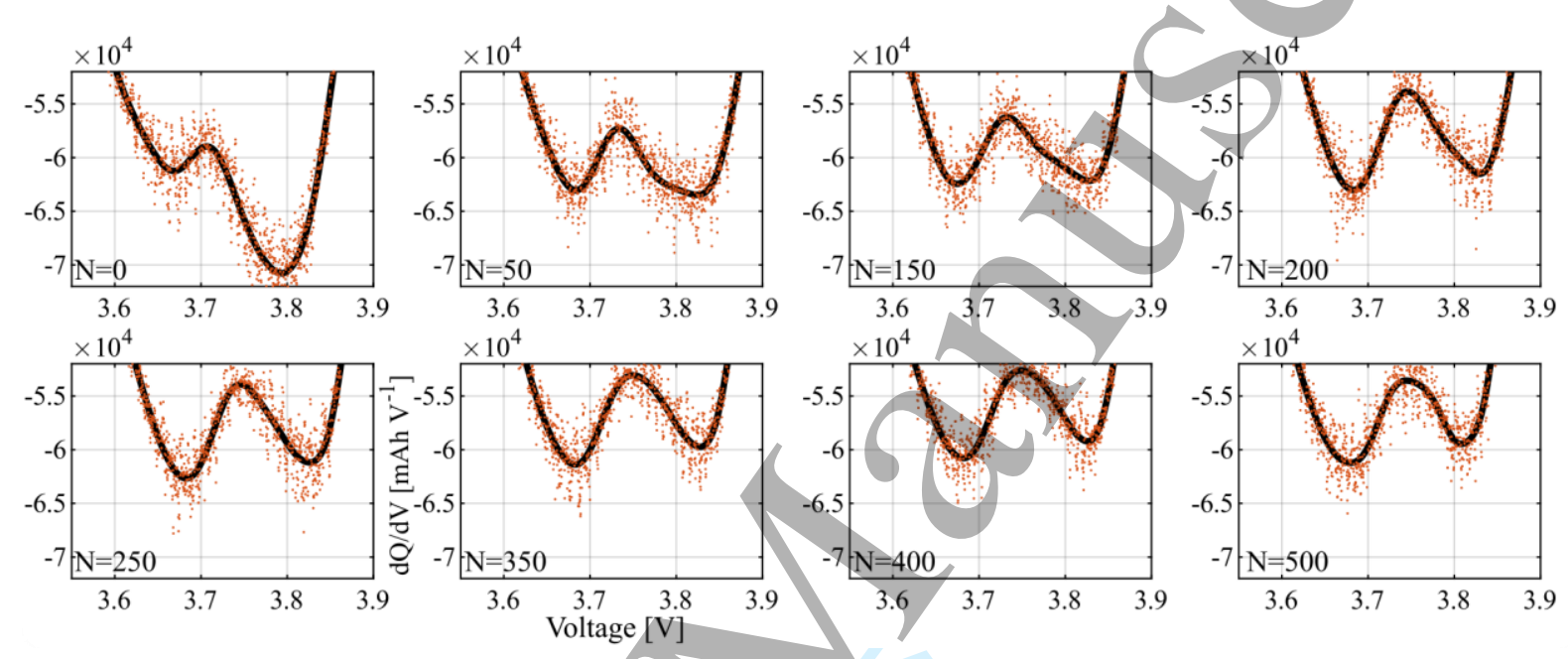

Figure 3. Incremental capacity analysis curves (non-filtered (dots) and filtered (solid line)) of the battery under the first cycling procedure $(\mathrm{CP} 1)$ for various cycles $(\mathrm{N})$.
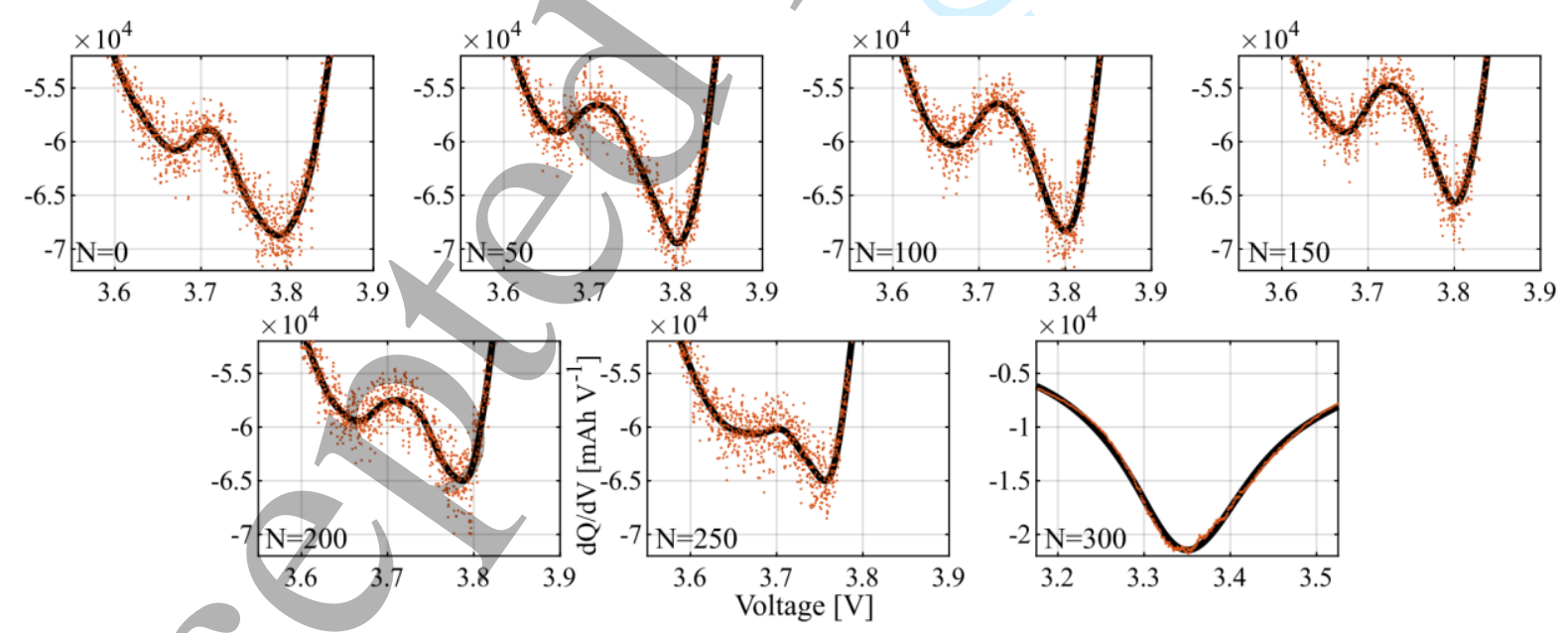

Figure 4. Incremental capacity analysis curves (non-filtered (dots) and filtered (solid line)) of the battery under the second cycling procedure $(\mathrm{CP} 2)$ for various cycles $(\mathrm{N})$.

To further analyse the ICA curves, the areas of A and B are evaluated and plotted against cycle number in Figure 5. Their evolution with cycle number and the linear fit is shown in 
Figures 5a and b for $\mathrm{CP} 1$ and $\mathrm{CP} 2$, respectively. For $\mathrm{CP} 1$, area $\mathrm{A}$ decreases quickly with cycle number up to 150 cycles followed by a slow and almost linear decay from 200 cycles onwards. However, area B increases up to 200 cycles before linearly and slowly decays afterward. For CP2, the behaviour of areas A and B is completely different as observed in Figure 5b. Here area A increases for the first 50 cycles and then decays linearly and rapidly after 50 cycles. Moreover, area B did not show a linear trend but bell-like type behaviour with a maximum of around 150 cycles. The evolution of area A and area B for CP1 and CP2 are shown in Figures $5 \mathrm{c}$ and d, respectively. The maximum value for area $\mathrm{B}$ is observed around 200 and 150 cycles for CP1 and CP2, respectively.
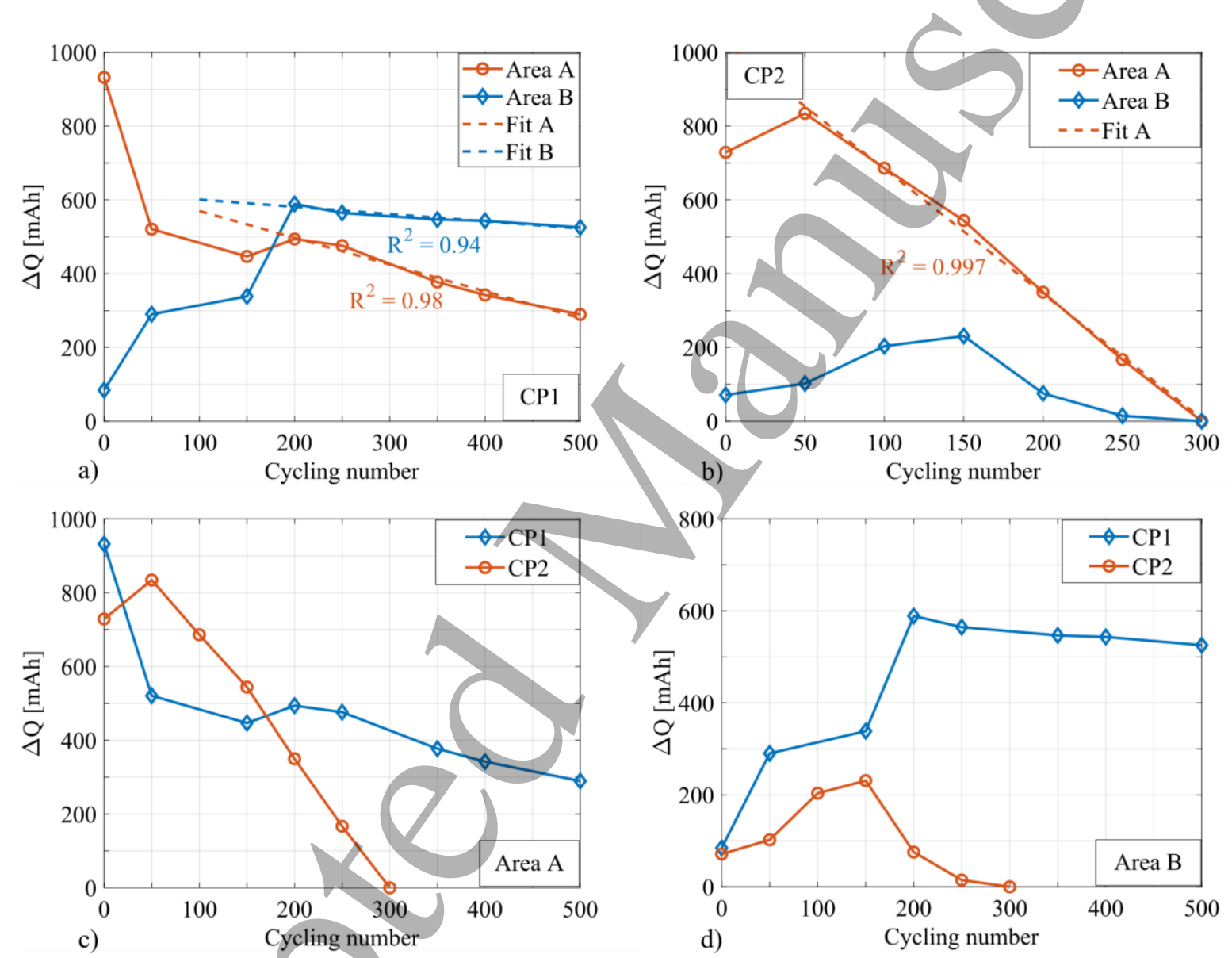

Figure 5. Evolution of areas $A$ and $B$ and their linear fit with cycle number in CP1 (a) and CP2 (b), (c) comparison of area $\mathrm{A}$ in $\mathrm{CP} 1$ and $\mathrm{CP} 2$, and (d) comparison of area $\mathrm{B}$ in $\mathrm{CP} 1$ and $\mathrm{CP} 2$.

In Figures 3-5, LLI and LAMs are occurring concomitantly in addition to conductivity loss (CL) since the investigation is beyond EV life and it is not straightforward to decouple these phenomena. ${ }^{36,42,43}$ The valley around $3.6 \mathrm{~V}$ is mainly influenced by the negative electrode and indicates the limiting electrode at the end of discharge, whereas the valley at $3.8 \mathrm{~V}$ reflects the main phase transformation on the positive electrode. ${ }^{37,44}$ Thus, area A and B involve with $\mathrm{LAM}_{\mathrm{PE}}$ and $\mathrm{LAM}_{\mathrm{NE}}$, respectively, combined with CL. The resistance growth 
due to increase thickness of the SEI layer responsible for LLI and possible dissolution of transition metal. ${ }^{45-48}$ In addition, the downturn observed in Figure $5 \mathrm{~d}$ may be indicative of lithium plating. ${ }^{36,49}$ A slow rate of lithium plating is expected for CP1 if any compared to CP2 which shows rapid decreases that lead further to the disappearance of the valleys. The new valley observed at $3.4 \mathrm{~V}$ for 300 cycles can be attributed to the destruction of the crystal structure induced by the dissolution of transition metals or the appearance of new phases or both.

\section{Thermal behaviour of aged LiBs}

For the analysis of temperature field change over the batteries' surfaces, two methods for ageing non-uniformity assessment are proposed based on the IR thermography. The first one is the standard deviation of temperature $\left(\sigma_{T}\right)$ over the battery surface and the second one is the analysis of the temperature rate over time $(d T / d t)$ maps. The latter can show more ageing non-uniformity compared to temperature over surface analysis because local heat generation rates are more visible on $d T / d t$ maps. Stemming from the noise elimination of measured temperature, every surface point temperature over time is approximated with $5^{\text {th }}$ order polynomial and $d T / d t$ maps over the discharging time were generated. Obtaining uniform temperature over the surface of the battery prior to measurement is not trivial. During measurements, it was observed that the temperature difference over the battery surface at the beginning of discharge was in the range of $0.5^{\circ} \mathrm{C}$ and $1^{\circ} \mathrm{C}$. To eliminate such temperature difference at the surface points, we have employed the relative temperature $\left(T_{r e l}\right)$ which can be expressed as:

$$
T_{\text {rel }}(x, y, t)=T_{m}(x, y, t)-T_{m}(x, y, 0)
$$

where $T_{m}(x, y, t)$ is a measured temperature in time $t$ at a point with image coordinates $x$ and $y$ and $T_{m}(x, y, 0)$ is a measured temperature at the same point at time $t=0$. Using the relative temperature, the standard deviation of temperature over the battery surface is expressed as:

$$
\sigma_{T}(t)=\sqrt{\frac{\sum_{i=0}^{x} \sum_{j=0}^{y}\left(T_{r e l}(i, j, t)-T_{a v g}(t)\right)^{2}}{x y}}
$$

where $T_{a v g}(t)$ is the relative average surface temperature at time $t$.

Figure 6 shows the relative temperature, its rate of change and the standard deviation of temperature as a function of charging time as well as the thermal maps of the relative temperature and its rate of change for discharging times at the beginning $(60 \mathrm{~s})$, in the middle 
(900 s) and at the end (1800 s) of discharge. It is seen that difference between points' $d T / d t$ values is more obvious than the difference between points' temperatures.
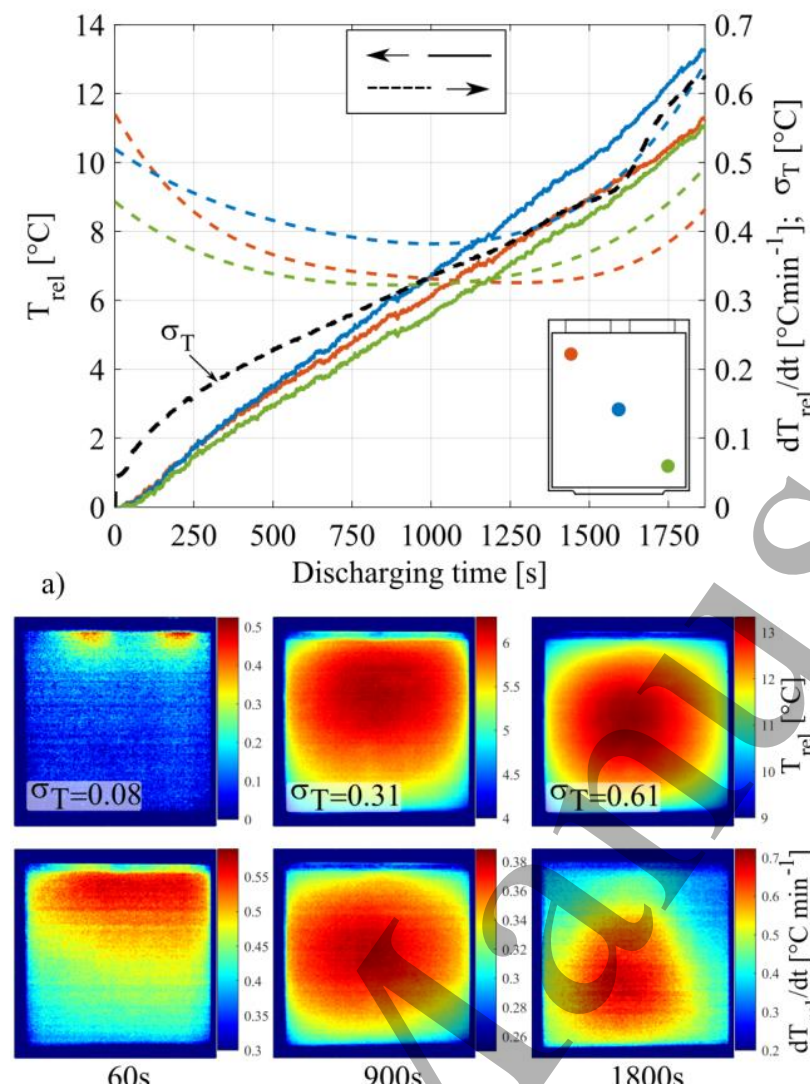

b)

Discharging time $[\mathrm{s}]$

Figure 6. (a) $\mathrm{T}_{\text {rel }}$ and $d T / d t$ at the battery surface three points and $\sigma_{\mathrm{T}}$ over the surface during discharging, (b) $\mathrm{T}_{\mathrm{rel}}$ and dT/dt maps and $\sigma_{\mathrm{T}}$ at $60 \mathrm{~s}, 900 \mathrm{~s}$ and $1800 \mathrm{~s}$ discharging times.

Figure 7 shows the calculated standard deviations of the temperature over the surface $\left(\sigma_{T}\right)$ for both cycled cells as a function of cell voltage. For CP1 (Figure 7a), two different trends of the $\sigma_{T}$ curve are identified. The first trend of the $\sigma_{T}$ curve is identified for the number of cycles (N) between 0 and 150 and the second one is observed between 200 and 500 cycles. Also, for $\mathrm{N}=0$ and $\mathrm{N}=250$ higher $\sigma_{T}$ value can be noticed at voltages from the beginning of discharging to $3.6 \mathrm{~V}$. This increase can be explained with different contact resistances between lead wires and tabs connections and it will be presented in $d T / d t$ maps section. For CP2 (Figure 7b), $\sigma_{T}$ values at the end of discharging are significantly higher compared to lower cycle numbers. At the beginning of discharging $\sigma_{T}$ value is decreasing with the cycling number for both cases and this difference is more obvious for CP2 (Figure 7b).

Figure 8 depicts the comparison of $\sigma_{T}$ and $d \sigma_{T} / d V$ at the beginning of cycling ( 0 cycle). As noted in Table 1, these cells had very similar capacities and positions in the module before 
cycling. Because of that, it is expected that their ageing state should be very similar. The first cell (later cycled with $\mathrm{CP} 1$ ) had higher $\sigma_{T}$ over the whole voltage range compared to the second cell (later cycled with CP2). Following $d \sigma_{T} / d V$ graphs, we can conclude that the $\sigma_{T}$ difference is caused by higher $d \sigma_{T} / d V$ values at the beginning of discharging for the first cell compared to the second cell. Between 3.8 and $3.5 \mathrm{~V}, d \sigma_{T} / d V$ values are almost identical. Four peaks on $d \sigma_{T} / d V$ graphs are identified and labeled as $\mathrm{P} 1, \mathrm{P} 2, \mathrm{P} 3$, and $\mathrm{P} 4$, as indicated in Figure 8 .
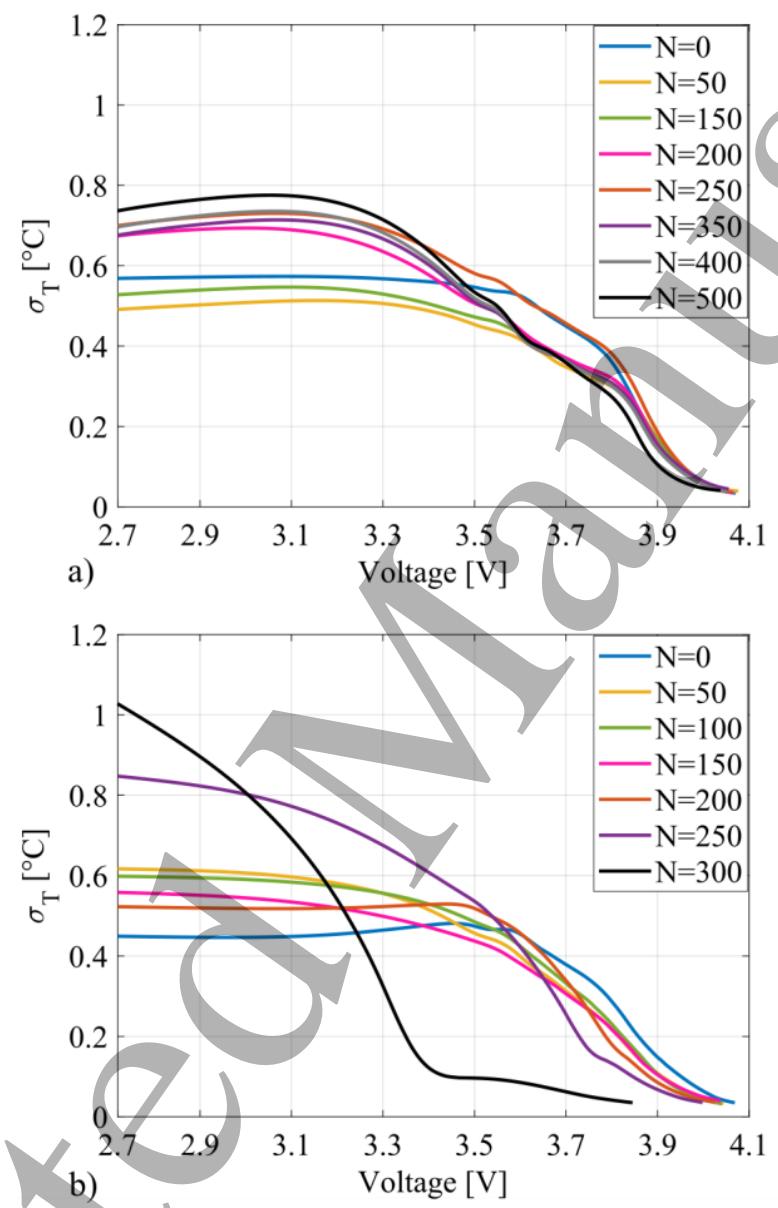

Figure 7. (a) $\sigma_{\mathrm{T}}$ versus voltage for cell cycled with CP1 cycling procedure and (b) $\sigma_{\mathrm{T}}$ versus voltage for cell cycled with $\mathrm{CP} 2$ cycling procedure.

Figures 9 and 10 present $d \sigma_{T} / d V$ as a function of voltage graphs for cells cycled for CP1 and CP2, respectively. The Savitsky-Golay algorithm is used for filtering purposes. The graphs shown are for a specific number of cycles at which changes are observed on the graphs from Figure 5. It is worth noting that the second peak P2 as indicated in Figure 8 is hardly seen in Figure 9 or distinguished from 0 to 150 cycles and it started to rise from 200 cycles onward. The P2 peak is obvious and increases significantly for 250 or higher cycles. Also, the rise of the peak P3 from 250-500 cycles is apparent. 


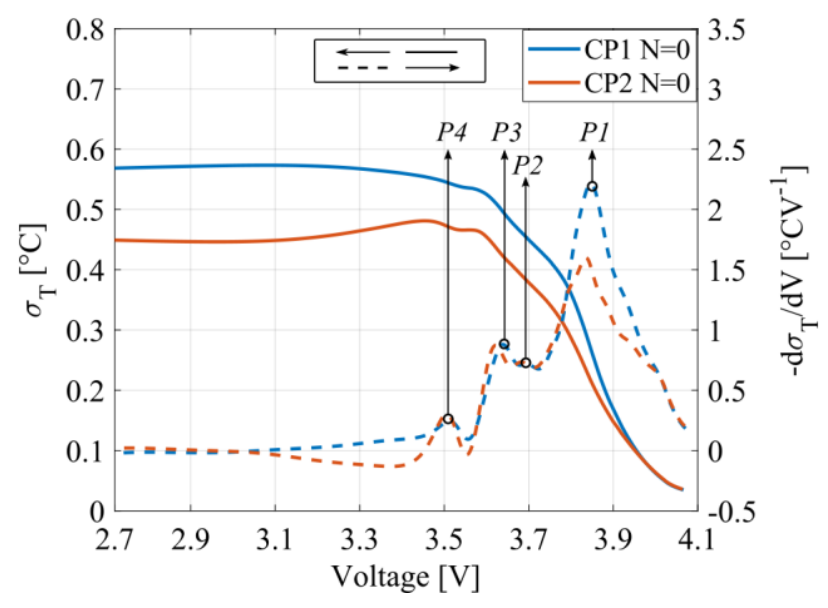

Figure 8. $\sigma_{\mathrm{T}}$ and $\mathrm{d} \sigma_{\mathrm{T}} / \mathrm{dV}$ for the cells before cycling $(\mathrm{N}=0)$.
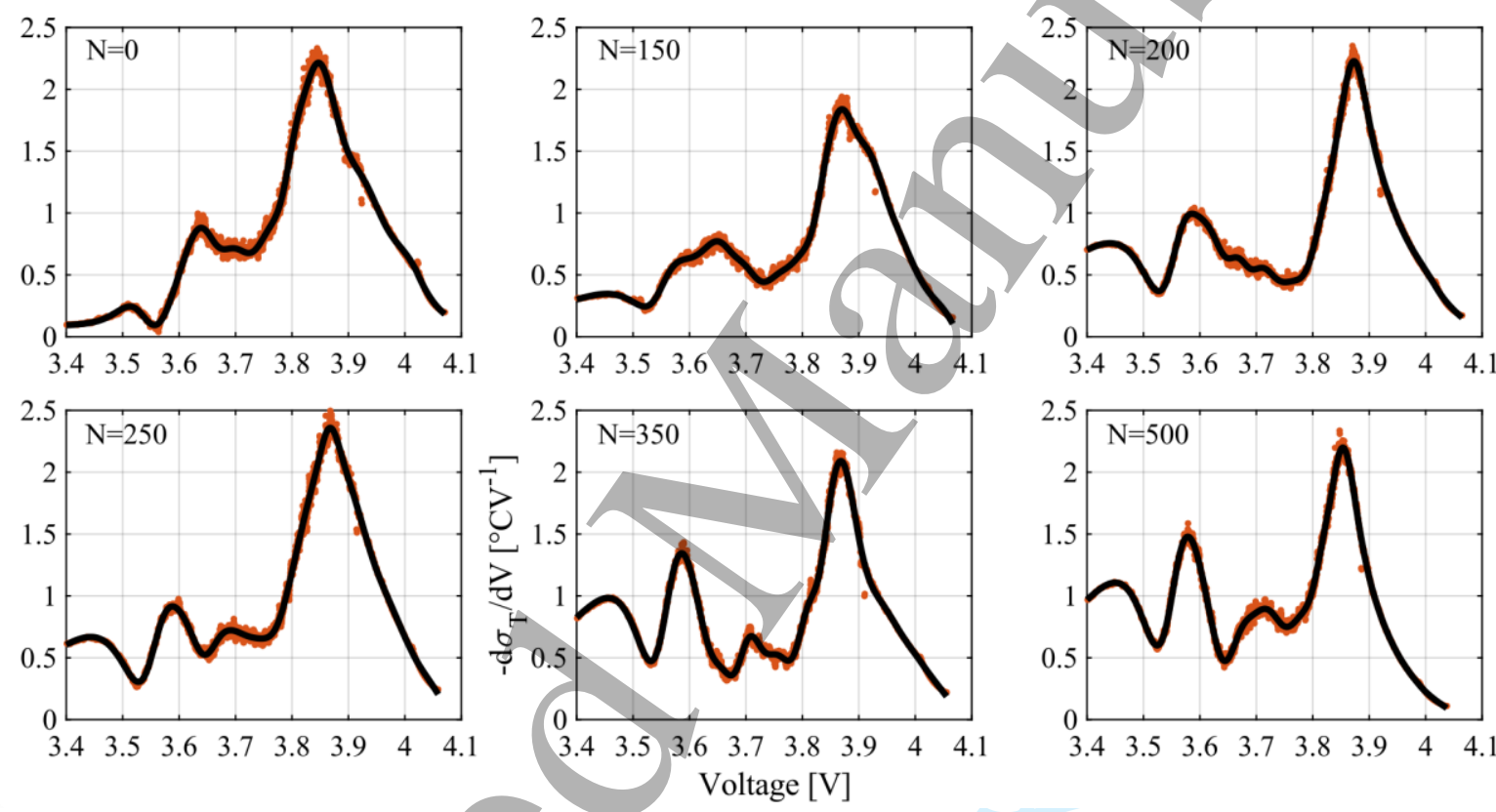

Figure 9. $\mathrm{d} \sigma_{\mathrm{T}} / \mathrm{dV}$ graphs (non-filtered (dots) and filtered (solid line)) for the cell cycled with $\mathrm{CP} 1$ cycling procedure.

For CP2 (Figure 10), the first peak P1, as indicated in Figure 8, slightly decreases with the cycle number and the rapid rising of peak $\mathrm{P} 2$ after $\mathrm{N}=150$ is observed. After 200 cycles, it is visible that peak $\mathrm{P} 2$ is higher compared to peak $\mathrm{P} 1$, and such a change in battery behaviour happened after only 50 cycles. The same trend is observed after 250 cycles where P2 increased and P1 decreased even more. It should be stated that after 300 cycles, the SoH for CP2 cycled cell drop to only $\sim 30 \%$. Clearly, some significant changes in the battery material happened which caused a change in the thermal behaviour of the CP2 cycled battery after 200 cycles. 

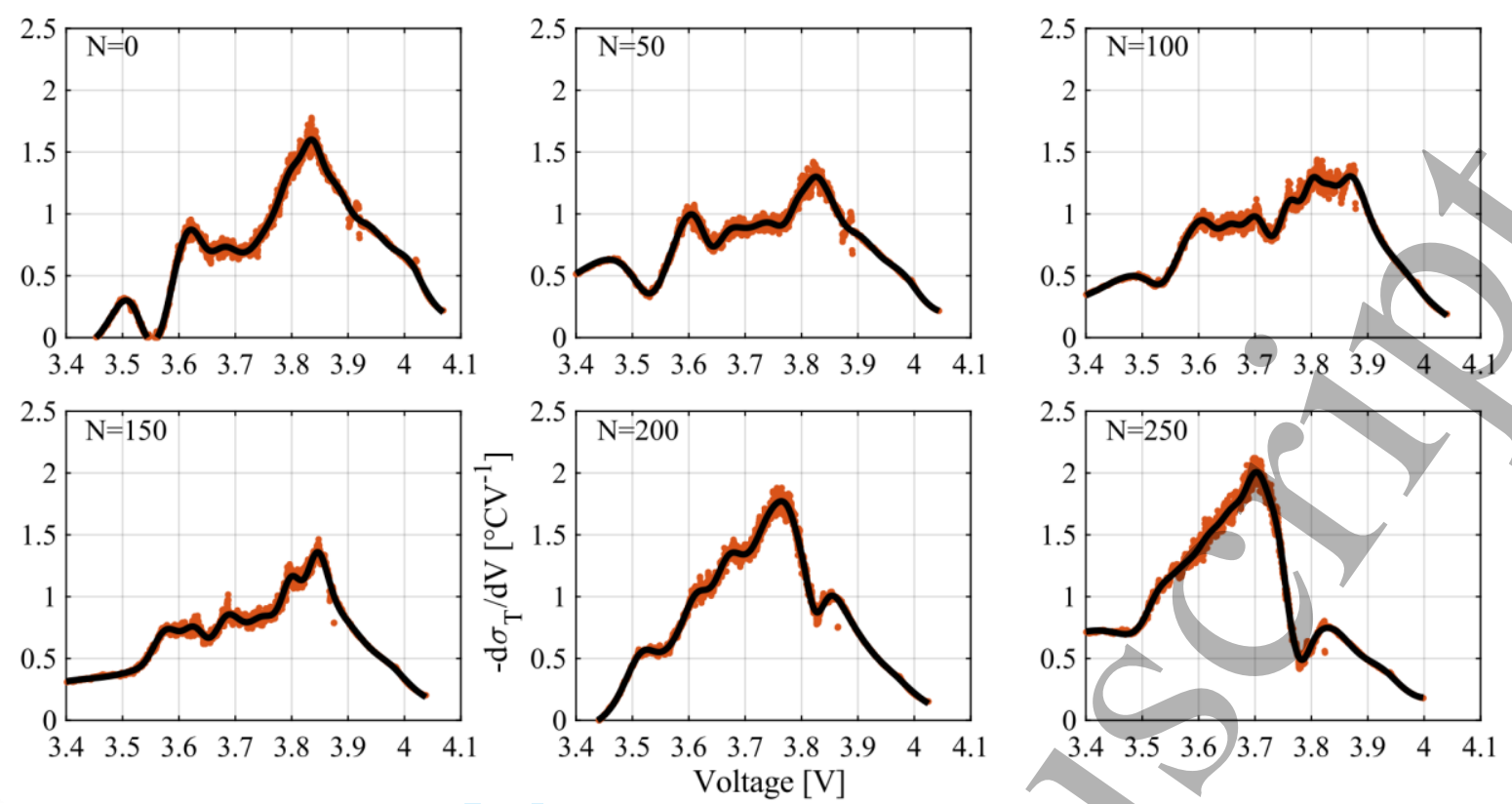

Figure 10. $d \sigma_{\mathrm{T}} / \mathrm{dV}$ graphs (non-filtered (dots) and filtered (solid line)) for the cell cycled with CP2 cycling procedure.

In Figure 11, normalised maps $d T / d t$ over the surface by $d T / d t_{\max }$ over surface value for the cycled cells are presented, where $d T / d t_{\max }$ on the maps has a value of 1 . Figure 11a shows the calculated maps at the beginning of the discharging $(60 \mathrm{~s})$. During that instance, the convective and radiative cooling can be neglected because of the very small difference between surface and ambient temperatures. There are only influences of the local heat generation rates and conduction on $d T / d t$ maps as well as the heat generation rate from the current collecting tabs. For $\mathrm{CP} 1, d T / d t$ maps have not changed significantly during cycling. For $\mathrm{CP} 2$, there is a noticeable change over the battery surface after 100 cycles and there is a significant change with increased map's values near the left, right and bottom battery edges after 200, 250 and 300 cycles. Figure 11b shows calculated maps at the end of discharging (10\% of SoC). Here, $d T / d t$ map's hot-spot position is a result of local heat generation rate, convective, radiative and tabs' cooling and conduction. From Figure 11b, it can be seen for CP1 that the hot spot has a regular circular shape and it is moving upwards with the number of cycles. For CP2, the hot-spot shape is more trapezoidal during the first 150 cycles and there are more cooling influences from the top of the cell (tabs) for both cells. After 200 cycles, $d T / d t$ map shape changed dramatically and after 250 cycles there are more cooling influences from the bottom of the cell. After 300 cycles there is more cooling from the tabs because discharging time was reduced dramatically, and tabs' temperature is significantly lower compared to the previous cycling numbers. 
In Figure 12, $d T / d t_{\max }$ values over the battery surface are presented. At the beginning of discharging, the area below the tabs will be heated more by the heat produced in tabs than from the heat generated in battery active material. ${ }^{18,22}$ The resistance in the active material will increase with ageing, causing an increase in the heat generated in the active material, and the total heat rate (from the active material and the tabs) should increase with the battery ageing. It is seen that for $\mathrm{CP} 1$ at $\mathrm{N}=0$ and 250 cycles and for $\mathrm{CP} 2$ at $\mathrm{N}=100$ cycles, $d T / d t_{\text {max }}$ values are higher at the beginning of discharge compared with adjacent cycling numbers. Because the same current is used during check-up procedures, these increased $d T / d t_{\text {max }}$ values can be explained with higher contact resistances between the tabs and lead wires during these measurements.

It is clear from the above results that the SoH based capacity does not elucidate the degradation mechanisms. However, the ICA technique allows detection at the level of the electrodes of different degradation mechanisms including LLI, LAMs and lithium plating. In $\mathrm{CP} 2$, prolong exposure at $4.4 \mathrm{~V}$ accelerated the electrolyte decomposition as opposed to $\mathrm{CP} 1$ and this increases SEI formation. Here the degradation of the electrolyte impacted ionic mobility as well as ion diffusion. Consequently, lithium-ion is deposited in the SEI which in turn increases the local resistances. We also believe that lithium plating will start to occur, and the overall process would generate non-uniformity in resistances and non-uniform current distribution and hence selective conduction pathways due to SEI thickness and loss in materials conductivity. Besides, results obtained by the two proposed IR techniques $\left(d \sigma_{T} / d V\right.$ and $d T / d t$ maps) show that the thermal behaviour of these batteries was quite different during ageing and are in support of the ICA. These thermal maps highlight the significance of nonuniform current distribution. Both IR techniques methods identified a significant change in the thermal behaviour of CP2 cycled battery after 200 cycles and while $d \sigma_{T} / d V$ detected quantitative change of trend line peak P2 (Figure 10), $d T / d t$ maps detected qualitative spacious change after same cycling number (Figure 11). Resistance non-uniformity over the battery surface influences higher current densities (and higher generated heat) around the SEI layer (Figure 11a blue area in the middle), which can be seen in the maps after 200, 250 and 300 cycles at the beginning of discharge. Also, plated lithium around the battery edges can change local thermal conductivities which can cause that heat from the tabs can be conducted more around the battery edges than through the middle of the battery at the beginning of discharge. All these non-uniformities can greatly contribute to battery failure. 

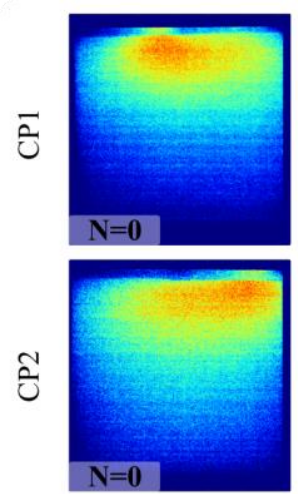

a)
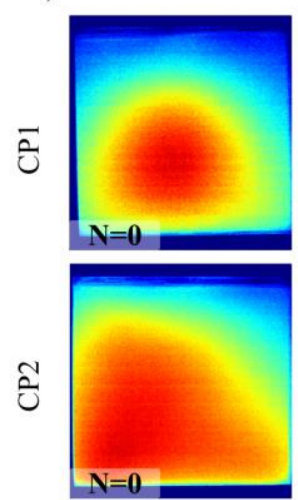

b)
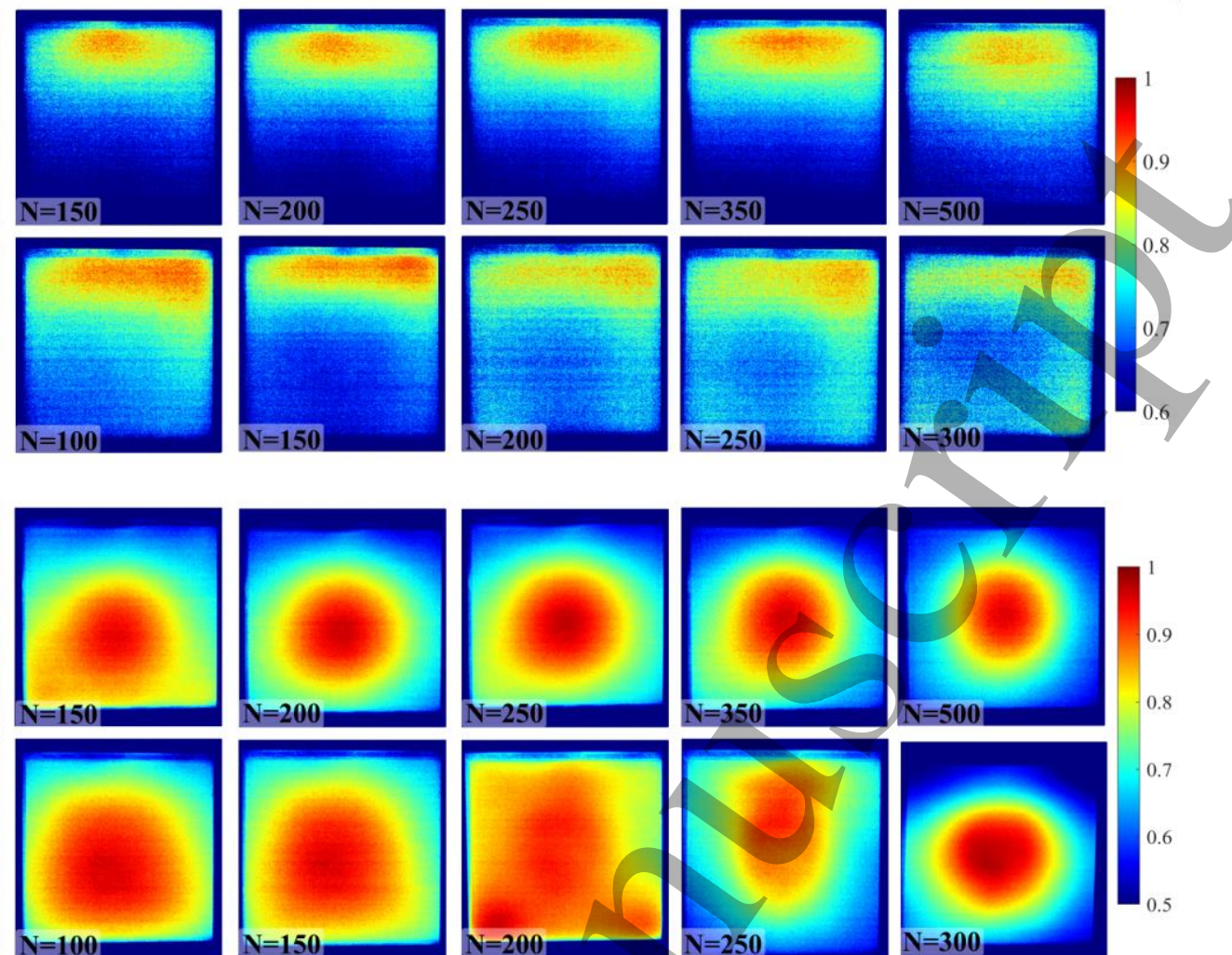

$\mathbf{N}=\mathbf{2 5}$

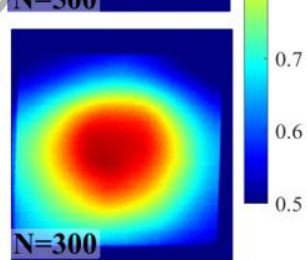

Figure 11. Normalised dT/dt maps for the cycled cells (a) at the beginning (60 s) of discharge, (b) at the end (10\% of SoC) of discharge, which highlights non-uniform heat generation due to non-uniform current distribution.

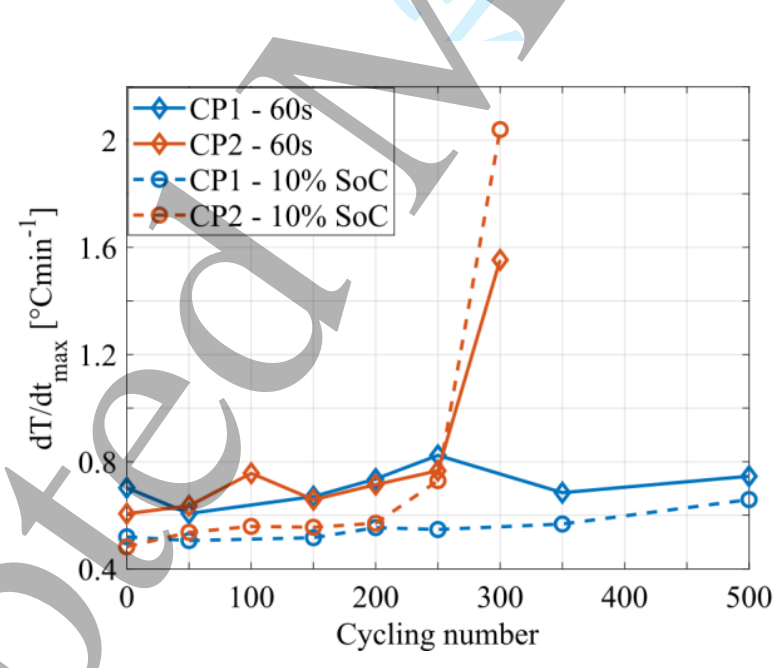

Figure 12. $\mathrm{dT} / \mathrm{d} \mathrm{t}_{\max }$ values at the beginning of discharging $(60 \mathrm{~s})$ and at the end of discharging $(10 \%$ of SoC).

\section{Conclusions}

In this work, several NDT methodologies for used EV-batteries that can be implemented in a gateway testing procedure on the second-life application before ultimate recycling have been investigated. Large-size pouch LiBs from a dismantled first-generation Nissan Leaf retired 
battery pack have been subjected to different accelerating ageing cycling procedures and the eventual faults developed indicating the "real" EoL are detected and evaluated. It is found that the cycling protocol is responsible for the degradation pathways that will lead to rapid or slow EoL. The capacity-based SoH gave information about capacity fade only. The electrode degradation and the "real" EoL were successfully detected by incremental capacity analysis and IR techniques. The results of both techniques independently indicate the cycle numbers at which the alarming point of these batteries cycled differently occurred and this correlates very well. The thermal information obtained from the battery surface temperature, standard deviation derivative over the voltage and temperature rate over the time maps can be utilised to detect quantitative changes or different qualitative spacious non-uniform aging changes over the large-size LiB's surface. These results consolidate and validate the ICA results. We think this study represents an important first step for "real" EoL detection that can be applied on large-size pouch cells with different chemistries and this is an area ripe for further exploration to achieve the full potential of used EV batteries.

\section{Acknowledgements}

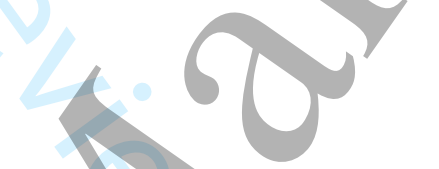

This work was part of the Recycling of Li-ion Batteries (ReLiB) project supported by the Faraday Institution grant ref: FIRG005.

\section{References}

1. L. C. Casals, B. A. García and C. Canal, J. Environ. Manage., 232, 354 (2019).

2. M. Muhammad, M. Ahmeid, P. S. Attidekou, Z. Milojevic, S. Lambert and P. Das, in 2019 IEEE 4th International Future Energy Electronics Conference (IFEEC), p. 1 (2019).

3. M. Berecibar, I. Gandiaga, I. Villarreal, N. Omar, J. Van Mierlo and P. Van den Bossche, Renew. Sust. Energ. Rev., 56, 572 (2016).

4. $\quad$ F. Yang, Y. Xie, Y. Deng and C. Yuan, Nat. Commun., 9, 1 (2018).

5. P. S. Attidekou, S. Lambert, M. Armstrong, J. Widmer, K. Scott and P. A. Christensen, J. Power Sources, 269, 694 (2014).

6. T. Momma, M. Matsunaga, D. Mukoyama and T. Osaka, J. Power Sources, 216, 304 (2012).

7. Q.-C. Zhuang, X.-Y. Qiu, S.-D. Xu, Y.-H. Qiang and S.-G. Sun, Lithium Ion Batteries-New Developments, 8, 189 (2012).

8. P. S. Attidekou, C. Wang, M. Armstrong, S. M. Lambert and P. A. Christensen, J. Electrochem. Soc., 164, A1792 (2017).

9. C. Weng, Y. Cui, J. Sun and H. Peng, J. Power Sources, 235, 36 (2013).

10. L. Zheng, J. Zhu, D. D.-C. Lu, G. Wang and T. He, Energy, 150, 759 (2018).

11. L. Zheng, J. Zhu, G. Wang, D. D.-C. Lu and T. He, Energy, 158, 1028 (2018). 
12. M. Wohlfahrt-Mehrens, C. Vogler and J. Garche, J. Power Sources, 127, 58 (2004).

13. C. R. Birkl, M. R. Roberts, E. McTurk, P. G. Bruce and D. A. Howey, J. Power Sources, 341, 373 (2017).

14. M. Ecker, P. S. Sabet and D. U. Sauer, Appl. Energy, 206, 934 (2017).

15. C. Meola, G. M. Carlomagno and L. Giorleo, J. Mater. Process. Technol., 155, 1132 (2004).

16. N. V. Aieta, P. K. Das, A. Perdue, G. Bender, A. M. Herring, A. Z. Weber and M. J. Ulsh, J. Power Sources, 211, 4 (2012).

17. P. K. Das, A. Z. Weber, G. Bender, A. Manak, D. Bittinat, A. M. Herring and M. Ulsh, J. Power Sources, 261, 401 (2014).

18. A. Rheinfeld, S. Kosch, S. V. Erhard, P. J. Osswald, B. Rieger and A. Jossen, J. Electrochem. Soc., 163, A3046 (2016).

19. M. Bouzin, M. Marini, A. Zeynali, M. Borzenkov, L. Sironi, L. D’Alfonso, F. Mingozzi, F. Granucci, P. Pallavicini and G. Chirico, Nat. Commun., 10, 1 (2019).

20. U. S. Kim, C. B. Shin and C.-S. Kim, J. Power Sources, 189, 841 (2009).

21. J. Yi, U. S. Kim, C. B. Shin, T. Han and S. Park, J. Electrochem. Soc., 160, A437 (2013).

22. S. Goutam, A. Nikolian, J. Jaguemont, J. Smekens, N. Omar, P. V. D. Bossche and J. Van Mierlo, Appl. Therm. Eng., 126, 796 (2017).

23. E. Hosseinzadeh, R. Genieser, D. Worwood, A. Barai, J. Marco and P. Jennings, J. Power Sources, 382, 77 (2018).

24. G.-H. Kim, K. Smith, K.-J. Lee, S. Santhanagopalan and A. Pesaran, J. Electrochem. Soc., 158, A955 (2011).

25. P. Taheri, A. Mansouri, B. Schweitzer, M. Yazdanpour and M. Bahrami, J. Electrochem. Soc., 160, A1731 (2013).

26. C. Veth, D. Dragicevic and C. Merten, J. Power Sources, 267, 760 (2014).

27. T. Waldmann, G. Bisle, B.-I. Hogg, S. Stumpp, M. A. Danzer, M. Kasper, P. Axmann and M. Wohlfahrt-Mehrens, J. Electrochem. Soc., 162, A921 (2015).

28. E. Martinez-Laserna, E. Sarasketa-Zabala, D.-I. Stroe, M. Swierczynski, A. Warnecke, J.-M. Timmermans, S. Goutam and P. Rodriguez, in 2016 IEEE Energy Conversion Congress and Exposition (ECCE), p. 1 (2016).

29. P. Arora, R. E. White and M. Doyle, J. Electrochem. Soc., 145, 3647 (1998).

30. P. Arora, M. Doyle and R. E. White, J. Electrochem. Soc., 146, 3543 (1999).

31. T. Liu, A. Dai, J. Lu, Y. Yuan, Y. Xiao, L. Yu, M. Li, J. Gim, L. Ma and J. Liu, Nat. Commun., 10, 1 (2019).

32. D. Juarez-Robles, A. Vyas, C. Fear, J. Jeevarajan and P. P. Mukherjee, J. Electrochem. Soc., 167, 090547 (2020).

33. E. Riviere, A. Sari, P. Venet, F. Meniere and Y. Bultel, Batteries, 5, 37 (2019).

34. K. A. Severson, P. M. Attia, N. Jin, N. Perkins, B. Jiang, Z. Yang, M. H. Chen, M. Aykol, P. K. Herring and D. Fraggedakis, Nat. Energy, 4, 383 (2019).

35. I. Bloom, L. K. Walker, J. K. Basco, D. P. Abraham, J. P. Christophersen and C. D. Ho, J. Power Sources, 195, 877 (2010).

36. M. Dubarry, C. Truchot and B. Y. Liaw, J. Power Sources, 219, 204 (2012).

37. M. Dubarry, C. Truchot and B. Y. Liaw, J. Power Sources, 258, 408 (2014).

38. Y. Jeon, H. K. Noh and H.-K. Song, Sci. Rep., 7, 1 (2017).

39. J. Kasnatscheew, T. Placke, B. Streipert, S. Rothermel, R. Wagner, P. Meister, I. C. Laskovic and M. Winter, J. Electrochem. Soc., 164, A2479 (2017).

40. Y. Abe and S. Kumagai, J. Energy Storage, 19, 96 (2018).

41. N. A. Samad, Y. Kim, J. B. Siegel and A. G. Stefanopoulou, J. Electrochem. Soc., 163, A1584 (2016). 
42. M. Dubarry, A. Devie and B. Y. Liaw, J. Energy Power Sources, 1, 242 (2014).

43. T. Plattard, N. Barnel, L. Assaud, S. Franger and J.-M. Duffault, Batteries, 5, 36 (2019).

44. Y. Gao, S. Yang, J. Jiang, C. Zhang, W. Zhang and X. Zhou, J. Electrochem. Soc., 166, A1623 (2019).

45. P. Arora, B. Popov and R. E. White, J. Electrochem. Soc., 145, 807 (1998).

46. M. Dubarry, V. Svoboda, R. Hwu and B. Y. Liaw, Electrochem. Solid-State Lett., 9, A454 (2006).

47. H. Zheng, Q. Sun, G. Liu, X. Song and V. S. Battaglia, J. Power Sources, 207, 134 (2012).

48. D. Anseán, M. Dubarry, A. Devie, B. Liaw, V. García, J. Viera and M. González, J. Power Sources, 321, 201 (2016).

49. D. Ren, X. Feng, L. Lu, M. Ouyang, S. Zheng, J. Li and X. He, J. Power Sources, 364, 328 (2017). 